\title{
Combination therapy of angiotensin-converting enzyme inhibitors and angiotensin II receptor blockers in chronic kidney disease
} Nina Vasavada ${ }^{1}$ and Rajiv Agarwal ${ }^{2 *}$

\author{
Addresses: ${ }^{1}$ Department of Public Health, University of Louisville, Louisville, KY 40202, USA; ${ }^{2}$ Division of Nephrology, Department of Medicine, \\ Indiana University School of Medicine and Richard L Roudebush VA Medical Center, Indiana University, Indianapolis, IN 46202, USA \\ *Corresponding author: Rajiv Agarwal (ragarwal@iupui.edu) \\ FI000 Medicine Reports 2009, I:47 (doi:I0.3410/MI-47)
}

The electronic version of this article is the complete one and can be found at: http://FI000.com/Reports/Medicine/content/l/47

\begin{abstract}
Dual blockade of the renin-angiotensin system (RAS) with a combination of angiotensin-converting enzyme inhibitors and angiotensin receptor blockers for the treatment of hypertension and proteinuria has been tested in several randomized trials among patients with chronic kidney disease (CKD). Although combination therapy reduces proteinuria and blood pressure, adequately powered studies evaluating time to end-stage renal disease, death, or cardiovascular outcomes in patients with CKD have not been done. Dual blockade of RAS can cause hyperkalemia, renal failure, and orthostatic hypotension and potentially worsen outcomes; therefore, the risk-benefit ratio in patients with CKD remains unclear. A recent randomized trial in patients with cardiovascular disease or highrisk diabetes raises concerns about the safety of this combination therapy.
\end{abstract}

\section{Introduction and context}

Long-term follow-up of subjects with chronic kidney disease (CKD) suggests that control of hypertension slows the progression of CKD [1]. In patients with CKD, angiotensin-converting enzyme (ACE) inhibitors and angiotensin receptor blockers (ARBs) lower blood pressure (BP) and also slow the progression of CKD $[2,3]$. It appears that progression of CKD in these patients may be due to effects beyond simply the lowering of $\mathrm{BP}$ [4]. ARBs, when added to ACE inhibitors, can effectively mitigate the increase in renin, angiotensin I, and angiotensin II concentrations that may occur with longterm ACE inhibition, referred to as 'ACE escape' [5]. Several small randomized trials evaluating the efficacy of dual blockade for the treatment of hypertension and/or proteinuria had found mixed results with generally low incidences of reported adverse events.

\section{Recent advances}

\section{Efficacy of dual renin-angiotensin system blockade}

Overall, in subjects with diabetic nephropathy, a metaanalysis found a favorable effect of dual renin- angiotensin system (RAS) blockade on BP. Systolic BP decreased by $4.2 \mathrm{~mm} \mathrm{Hg}$ (95\% confidence interval [CI] 1.1 to 7.2 ), and diastolic BP decreased by $2.8 \mathrm{~mm} \mathrm{Hg}$ (95\% CI 1.2 to 4.6$)$. In subjects with nondiabetic proteinuric CKD, the pooled mean systolic BP decreased by $4.9 \mathrm{~mm} \mathrm{Hg}$ (95\% CI 2.7 to 7.2 ) and the diastolic BP decreased by $2.0 \mathrm{~mm} \mathrm{Hg}$ (95\% CI 1.2 to 2.9 ) when an ARB was added to an ACE inhibitor [6]. Pooled estimates of 24-hour urinary protein excretion demonstrate an additional reduction of $440 \mathrm{mg} /$ day (95\% CI 289 to 591) from dual RAS blockade compared with ACE inhibitor monotherapy [6]. In subjects with diabetes mellitus (DM), this additional reduction was estimated at $210 \mathrm{mg} /$ day (95\% CI 84 to 336), whereas in subjects with nondiabetic proteinuric kidney disease, an additional $582 \mathrm{mg} /$ day (95\% CI 371 to 793 ) reduction was observed [6]. The greater reduction in proteinuria among patients with nondiabetic CKD is unknown but is likely not due to a greater reduction in BP in these patients. A more recent meta-analysis confirmed the favorable effect of dual RAS on reduction in proteinuria over the course of 12 months when compared with monotherapy 
in both nondiabetics and subjects with DM, independent of the level of baseline proteinuria [7].

In general, dual blockade leads to a reduction in proteinuria but significant heterogeneity is seen among trials [7]. For example, Agarwal [8] did not observe a reduction in proteinuria in older people with more severe kidney disease whereas Mogensen et al. [9] observed a reduction in albuminuria when studying diabetics with microalbuminuria. Accordingly, it is quite possible that the reduction in proteinuria seen with combination therapy may be a function of the severity of kidney disease. In this context, albuminuria and glomerular filtration rate (GFR) are two separate measures of severity of kidney disease. Characterizing the severity of CKD on both of these measures of renal function could influence hard outcomes, and this should be tested in future meta-analyses and clinical trials.

Perhaps the most promising trial supporting the role of combination therapy was that reported by Nakao et al. [10], who conducted a 3-year randomized trial called COOPERATE (combination treatment of angiotensin II receptor blocker and angiotensin-converting enzyme inhibitor in nondiabetic renal disease). The trial randomly assigned 263 Japanese subjects to receive losartan $100 \mathrm{mg}$, trandolapril $3 \mathrm{mg}$, or both for 3 years. This large, relatively long trial found similar BP effects in study cohorts treated with combination therapy versus monotherapy, but spectacular effects on rates of progression of CKD were reported. The primary endpoint of doubling of serum creatinine or end-stage renal disease was seen in 10 of 85 patients $(11 \%)$ on combination treatment compared with 20 of 85 on trandolapril alone (23\%) (hazard ratio [HR] $0.38,95 \%$ CI 0.18 to $0.63, P=0.018$ ) and 20 of 86 on losartan alone (23\%) (HR 0.40, 95\% CI 0.17 to $0.69, P=0.016$ ). However, serious concerns regarding the authenticity of this trial have been raised, prompting the observation by the authors that originally published BP data were erroneous due to data management and other errors $[11,12]$.

\section{Safety of dual renin-angiotensin system blockade}

Reporting of adverse events has been variable between dual RAS blockage studies, with a recent meta-analysis finding that only $33 \%$ of trials included reported methods of assessing adverse events. Of these, the most frequently reported reasons for discontinuing medications were dizziness, hyperkalemia, cough, allergies, and hypertensive episodes [7]. Generally, smaller trials of shorter duration have reported minimal adverse events. Most trials assessing BP effect in subjects with CKD have followed participants for 12 weeks or less, although one trial of dubious quality followed subjects for 3 years as discussed above [10]. In a meta-analysis by Mackinnon et al. [6], the pooled decrease of estimated GFR (eGFR) with combination therapy was $-1.4 \mathrm{~mL} /$ minute $(95 \%$ CI -2.6 to 0.2 ). Pooled potassium data reveal a small but statistically significant rise in serum potassium of $0.11 \mathrm{mmol} / \mathrm{L}(95 \%$ CI 0.05 to 0.17$)$ [6].

The enthusiasm for dual RAS blockade has been tempered by a large randomized double-blinded trial that demonstrated a significant rate of serious adverse events $[13,14]$. The Ongoing Telmisartan Alone and in combination with Ramipril Global Endpoint Trial (ONTARGET) evaluated the combination of the ACE inhibitor ramipril with the ARB telmisartan in 25,620 subjects (at least 55 years old) with established atherosclerotic vascular disease or with diabetes with end organ damage. Mean serum creatinine of the study cohort was $93 \mu \mathrm{mol} / \mathrm{L}$, and microalbuminuria was present in $13 \%$ of subjects. Exclusion criteria included serum creatinine of greater than $265 \mu \mathrm{mol} / \mathrm{L}$ and uncontrolled hypertension ( $>160 / 100 \mathrm{~mm} \mathrm{Hg}$ ) on treatment [15]. Subjects were randomly assigned to receive telmisartan $80 \mathrm{mg} /$ day, ramipril $10 \mathrm{mg} /$ day, or both. Participants were followed for a median of 56 months. At baseline, the mean BP was 141.8/ $82.1 \mathrm{~mm} \mathrm{Hg}$ in each treatment group. BP was reduced at 6 weeks by $6.4 / 4.3 \mathrm{~mm} \mathrm{Hg}$ in the ramipril group, by $7.4 / 5.0 \mathrm{~mm} \mathrm{Hg}$ in the telmisartan group, and by $9.8 /$ $6.3 \mathrm{~mm} \mathrm{Hg}$ in the combination therapy group. Progression of baseline microalbuminuria to macroalbuminuria was significantly attenuated in the combination group versus the ramipril group (HR 0.76, 95\% CI 0.60 to $0.96, P=0.019$ ), with no differences between ramipril and telmisartan [13]. Most of the small numbers of events in this large trial were due to acute renal failure, not end-stage renal disease. Notably, this trial also excluded patients with more advanced CKD.

In contrast, the incidence of the primary renal composite outcome (any dialysis, renal transplantation, doubling of serum creatinine, or death) increased with combination therapy $(14.5 \%$ of subjects taking combination therapy; HR $1.09,95 \%$ CI 1.01 to $1.18, P=0.037$ ). Secondary renal outcomes included changes in eGFR and progression of proteinuria [13]. Over the initial 2 years of the trial, eGFR was significantly worse in both the telmisartan and combination groups when compared with ramipril alone $(P<0.0001)$. Renal abnormalities were reported in significantly higher numbers in the combination therapy group than in the ramipril cohort (ramipril 10.2\%, telmisartan $10.6 \%$, and combination therapy $13.5 \%, P<0.001)$ and those renal abnormalities were severe enough to necessitate permanently stopping medication $(0.7 \%, 0.8 \%$, and $1.1 \%$, 
respectively, $P<0.005$ ). Hyperkalemia (serum potassium $>5.5 \mathrm{mmol} / \mathrm{L}$ ) was worse in the combination therapy group $(P<0.001)$ versus the ramipril group; no significant differences were observed between the ramipril and telmisartan groups [14]. The incidence of acute dialysis was significantly greater in the combination group than in the ramipril group (HR 2.19, 95\% CI 1.13 to $4.22, P=0.02$ ) and was similar in the ramipril and telmisartan groups. There were no differences between groups with respect to incidence of chronic dialysis [13].

\section{Implications for clinical practice}

Although several trials have affirmed efficacy for BP reduction, recent unfavorable safety data cast doubt on the suitability of chronic dual RAS blockade in patients with vascular disease and low levels of proteinuria. Although the ONTARGET study did not address subjects with advanced CKD and/or proteinuria, it seems plausible that the safety profile of combination therapy would be relevant to this patient population. This trial suggests that dual blockade should be avoided in patients with cardiovascular disease and those with high-risk diabetes. However, since patients with more advanced CKD or those with severe proteinuria were not studied, the results of this trial do not apply to these patients. Nonetheless, they raise the concern that surrogate endpoints are not sufficient when judging the safety and efficacy of dual blockade. Ongoing trials may better illuminate the safety and efficacy of combination therapy on hard endpoints among patients with CKD $[16,17]$.

Patients who are currently stable on combination therapy present a management dilemma. Certainly, an agent should be discontinued if sudden deterioration of kidney function, hyperkalemia, hypotension, or hypotensive symptoms such as syncope are noted.

\section{Abbreviations}

$\mathrm{ACE}$, angiotensin-converting enzyme; $\mathrm{ARB}$, angiotensin receptor blocker; $\mathrm{BP}$, blood pressure; $\mathrm{CI}$, confidence interval; $\mathrm{CKD}$, chronic kidney disease; $\mathrm{DM}$, diabetes mellitus; eGFR, estimated glomerular filtration rate; GFR, glomerular filtration rate; HR, hazard ratio; ONTARGET, Ongoing Telmisartan Alone and in combination with Ramipril Global Endpoint Trial; RAS, renin-angiotensin system.

\section{Competing interests}

RA has been a consultant to Boehringer Ingelheim GmbH (Ingelheim, Germany) and a speaker for Merck \& Co, Inc (Whitehouse Station, NJ, USA). NV declares that she has no competing interests.

\section{References}

I. Sarnak MJ, Greene T, Wang X, Beck G, Kusek JW, Collins AJ, Levey AS: The effect of a lower target blood pressure on the progression of kidney disease: long-term follow-up of the modification of diet in renal disease study. Ann Intern Med 2005, I42:342-5I.

2. Brenner BM, Cooper ME, de ZD, Keane WF, Mitch WE, Parving HH, Remuzzi G, Snapinn SM, Zhang Z, Shahinfar S: Effects of losartan on renal and cardiovascular outcomes in patients with type 2 diabetes and nephropathy. N Engl J Med 200I, 345:86I-9.

3. Agodoa LY, Appel L, Bakris GL, Beck G, Bourgoignie J, Briggs JP, Charleston J, Cheek D, Cleveland W, Douglas JG, Douglas M, Dowie D, Faulkner M, Gabriel A, Gassman J, Greene T, Hall Y, Hebert L, Hiremath L, Jamerson K, Johnson C], Kopple J, Kusek J, Lash J, Lea J, Lewis JB, Lipkowitz M, Massry S, Middleton J, Miller ER III: Effect of ramipril vs amlodipine on renal outcomes in hypertensive nephrosclerosis: a randomized controlled trial. JAMA 200I, 285:2719-28.

4. Cohn JN, Goldman JM: Establishing a new option for targetorgan protection: rationale for ARB plus ACE inhibitor combination therapy. Am J Hypertens 2008, 2 I:248-56.

5. Nussberger J, Brunner DB, Waeber B, Brunner HR: Plasma angiotensins under sustained converting enzyme inhibition with enalapril in normal humans. J Hypertens Suppl 1985, 3:S269-S270.

6. MacKinnon M, Shurraw S, Akbari A, Knoll GA, Jaffey J, Clark HD: Combination therapy with an angiotensin receptor blocker and an ACE inhibitor in proteinuric renal disease: a systematic review of the efficacy and safety data. Am J Kidney Dis 2006, 48:8-20.

7. Kunz R, Friedrich C, Wolbers M, Mann JF: Meta-analysis: effect of monotherapy and combination therapy with inhibitors of the renin angiotensin system on proteinuria in renal disease. Ann Intern Med 2008, I48:30-48.

8. Agarwal R: Add-on angiotensin receptor blockade with maximized ACE inhibition. Kidney Int 200I, 59:2282-9.

9. Mogensen CE, Neldam S, Tikkanen I, Oren S, Viskoper R, Watts RW, Cooper ME: Randomised controlled trial of dual blockade of renin-angiotensin system in patients with hypertension, microalbuminuria, and non-insulin dependent diabetes: the candesartan and lisinopril microalbuminuria (CALM) study. BMJ 2000, 32 I: |440-4.

10. Nakao N, Yoshimura A, Morita H, Takada M, Kayano T, Ideura T: Combination treatment of angiotensin-II receptor blocker and angiotensin-converting-enzyme inhibitor in non-diabetic renal disease (COOPERATE): a randomised controlled trial. Lancet 2003, 36 I: I 17-24.

II. Bidani A: Controversy about COOPERATE ABPM trial data. Am J Nephrol 2006, 26:629, 632; author reply 629-32.

12. Kaplan NM: Recent clinical trials: the good, the bad, and the misleading. Hypertension 2008, 52:608-9.

I3. Mann JF, Schmieder RE, McQueen M, Dyal L, Schumacher H, Pogue J, Wang X, Maggioni A, Budaj A, Chaithiraphan S, Dickstein K, Keltai M, Metsarinne K, Oto A, Parkhomenko A, Piegas LS, Svendsen TL, Teo KK, Yusuf S: Renal outcomes with telmisartan, ramipril, or both, in people at high vascular risk (the ONTARGET study): a multicentre, randomised, double-blind, controlled trial. Lancet 2008, 372:547-53.

Changes Clinical Practice

Factor 8.4 Exceptional

Evaluated by William Mitch 02 Sep 2008, Enyu Imai 05 Sep 2008, Luis Ruilope 13 Nov 2008, Neil Turner 06 Apr 2009

14. Yusuf S, Teo KK, Pogue J, Dyal L, Copland I, Schumacher H, Dagenais G, Sleight $P$, Anderson $C$ : Telmisartan, ramipril, or both in patients at high risk for vascular events. N Engl J Med 2008, 358:I 547-59.

FI000 Factor 10.0 Exceptional Evaluated by Csaba Kovesdy 15 Apr 2008, Sripal Bangalore 23 Apr 2008, Enyu Imai 06 May 2008, Ernie Esquivel I4 May 2008

15. Teo K, Yusuf S, Sleight P, Anderson C, Mookadam F, Ramos B, Hilbrich L, Pogue J, Schumacher H: Rationale, design, and baseline 
characteristics of 2 large, simple, randomized trials evaluating telmisartan, ramipril, and their combination in high-risk patients: the Ongoing Telmisartan Alone and in Combination with Ramipril Global Endpoint Trial/Telmisartan Randomized Assessment Study in ACE Intolerant Subjects with Cardiovascular Disease (ONTARGET/TRANSCEND) trials. Am Heart J 2004, I48:52-6I.
16. Berns JS: Is angiotensin-converting enzyme inhibitor and angiotensin receptor blocker combination therapy better than monotherapy and safe in patients with CKD? Am J Kidney Dis 2009, 53:192-6.

17. Arici M, Erdem Y: Dual blockade of the renin-angiotensin system for cardiorenal protection: an update. Am J Kidney Dis 2009, 53:332-45. 